\title{
Las Dos Orillas de Julio Cortázar
}

\author{
ENSAyo de IA CONQuista de UN Espacio
}

La Tierra y el Cielo son algo menos que las dos esferas abiertas al gran vacio que separa sus orillas;

pero la Tierra y el Cielo son, también, algo más que la distancia que puede recorrer con habilidad un niño empujando una piedrita en el cuadriculado de una rayuela dibujada con tiza en un patio o una calleja;

puede ser $-y$ es en la obra de Julio Cortázar - una suerte de ubicua y burlona aspiración vertical, una tendencia que orienta una búsqueda del centro de todo protagonista previamente descolocado. El éxtasis del viaje que la búsqueda del propio "omphalos" provoca, recorre sin dramatismo y con cierta alegría infantil los extremos de un "eje" que comunica a Los reyes con Rayuela, del mismo modo que comunica (aproximándolos) a la Tierra con el Cielo y su paralelo cartográfico, Buenos Aires (un "abajo" del mapa, tal vez una forma posible del Infierno) con el otro Cielo posible: París.

Descubiertas las "galerías" secretas que comunican uno y otro extremo de la obra de Cortázar, al mismo tiempo que proponen una suerte de comunicación posible entre los polos que componen dos densidades de larga simbología mítica, el esquema vertical se inscribe fácilmente en una tradición literaria que el narrador argentino integra: el "destierro" del rioplatense.

Estas "dos orillas" enfrentadas -América y Europa entrecruzadas-, a su vez, con la búsqueda personal del propio centro dividido en los extremos de un eje que intenta comunicar la Tierra con el Cielo, proponen un inesperado esquema a la rica y variada obra de Cortázar e inscriben a su particular espacio novelesco en una triple dimensión estructural, cuyo desguazamiento es no menos apasionante que su planteo. 


\section{EL Destierro Americano}

Algo epigonal del típico "outsider" existencial parece estar subyaciendo en el origen de la actitud del personaje de Cortázar descolocado en relación a su realidad original: estar "desterrado" en América, echado a la orilla de un río barroso, abierto a un océano que lo separa de la otra orilla de la que guarda una secreta nostalgia: Europa. Este desterrado es en buena parte un héroe que participa de la condición del "homo absurdus" del que hablaba Nathalie Sarraute. El hombre marcado por el triple determinismo del hombre, la sexualidad y. la clase social, es decir, influido por Pavlov, Freud y Marx; el héroe que participa de esa compleja "Teología de la Crisis" que inaugura Kierkegaard y culmina en Karl Barth.

Esta descolocación ha sido llamada por el propio Cortázar "el sentimiento de no estar del todo en cualquiera de las estructuras, de las telas que arma la vida y en las que somos a la vez araña y mosca."1 Ese sentimiento de "no estar del todo" 'instala obligadamente a sus personajes en una especie de "punto cero", una descolocación de la rutina, un corte con el contorno, que pueden permitir a la Maga de Rayuela enrostrarle a un "descolocado" Horacio Oliveira:

Vos sos como un testigo, sos el que va al museo y mira los cuadros. Quiere decir que los cuadros están ahí y vos en el museo, cerca y lejos al mismo tiempo. Yo soy un cuadro, Rocamadour es un cuadro: Etienne es un cuadro, esta pieza es un cuadro. Vos creés que estás en esta pieza pero no estăs. Vos estás mirando la pieza, no estás en la pieza

El hecho de estar "descolocado" no basta; lo importante es concientizarlo en forma adecuada, y esto es, justamente, lo que le sucede a Horacio cuando se dice con tristeza:

feliz de ella que podía creer sin ver, que formaba cuerpo con la duración, el continuo de ta vida. Feliz de ella que estaba dentro de la pieza, que tenía derecho de ciudad en todo lo que tocaba y convivia, pez río abajo, hoja en el árbol, nube en el cielo, ima-

1 La vuelta al dia en ocbenta mundos (México: Siglo XXI Editores, p. 21).

2 Rayuela, p. 29 . Todas las citas correspondientes a esta novela son de la edición de "Casa de las Américas" (La Habana, Cuba; 1969). 
gen en el poema. Pez, nube, imagen: exactamente eso, a menos que. ...

Algún crítico ha visto en esta "descolocación" del personaje de Cortázar una expresión de la propia actitud del escritor en la vida. Cortázar aparecería sobrepuesto a la predestinación de pertenecer a una comunidad y convivir en este nuevo medio, pero no integrado absolutamente a ella y conservando un lazo con el grupo original. Esa desambientación sería la generadora de un proceso literario según el cual el creador sa autodestruye y se configura nuevas imágenes, nuevas perspectivas, las que vuelve a destruir, sucesiva y permanentemente.

Pero esta imposibilidad de "estar del todo" puede provocar en otros relatos de Cortázar, justamente el absurdo de su opuesto: el espectador que mira como "testigo" (desde afuera) el movimiento del exótico pez mexicano -el "axolotl", en el relato del mismo nombre- puede llegar a abolir esa distancia para terminar él mismo transformado en la imagen que está detrás del vidrio del acuario. Sin embargo, analizando en profundidad el proceso, el absurdo de la oposición es tan sólo una apariencia de oposición; el protagonista de "Axolotl" ha abolido una distancia, si, pero para descolocarse aủn más. En vez de lograr obtener una aproximación natural a lo que podría ser su propio contorno (algo que no puede lograr, aparentemente, ningún personaje de Cortázar), agudiza su original irrealidad transmutándose en un animal aún más exótico que su primera descolocación.

\section{EL. INADAPTADO COMO "CLOWN"}

Pero no hay que alarmarse: el "inadaptado" tepresentativo de una vasta tradición literaria que Cortázar compone, asume en todos los casos un nivel de actuación más paródico que seriamente dramático. Ia "concientización" de la descolocación se traduce en una búsqueda del propio centro, un modo de insertarse en la realidad, pero el medio asumido como vehículo no es preocupado, sino que es parte de una "representación", tal como se dice del actor o del "clown".

Como ha destacado Jean Jacques Mayoux a propósito de los personajes de Samuel Beckett esta representación paródica es el único recurso para integrarse en una realidad que los rechaza y a la que han perdido acceso. Parodia de actividades "serias", la presunta seriedad

s lbid., p. 29. 
de la vida aparece distorsionada aún más por la vía del humor $\mathrm{y}$ del ridículo, una imitación sutil de aquello en que ya no puede creer intimamente el protagonista "clochard" de que habla Jean Bloch Michel en Le present de lindicatif y que encarna típicamente el Horacio Oliveira de Rayutela.

Esta inevitable "neutralización" de la solemnidad del gesto existencial que la parodia cortazariana provoca no supone, sin embargo, que la búsqueda cese o que la "representación" con que se la inviste, traducida en juego, pierda seriedad.

\section{El Juego "Significante" y su Sentido Mágico}

La función paródica, agudiza aún más la previa descolocación de la quie partimos en este esquema de la obra de Cortázar, pero una de sus expresiones -el juego- habrá de convertirse en un modo de colocación.

Porque un juego, bien mirado, ino es un proceso que parte de una descolocación para llegar a una colocación, a un emplazamiento -gol, jaque mate, piedra libre? ¿No es el cumplimiento de una ceremonia que marcha hacia la fijación final de la corona?s

De ahí la importancia de la rayuela en Rayuela, pero también la de otros posibles juegos, tal como se proyecta en Los premios.

Volvemos a la noción de juego. Supongo que forma parte de la concepción actual de la vida, sin ilusiones y sin trascendencia. Uno se conforma con ser un buen alfil o una buena torrel, correr en diagonal o enrocar para que se salve el rey. ${ }^{5}$

El elemento juego recorre muchas otras páginas de Cortázar y se expresa en enfrentamientos de libertad-azar, juego-realidad, culpa-providencialismo, o como simple posibilidad de "violar lo previsto" como señala Graciela de Sola a propósito de "Instrucciones para John Howell". En uno y otro caso el juego que propone Cortázar es en el sentido mágico que han entendido muchos autores del surrealismo. No es el despliegue de un mero goce circunstancial o traguito, es un juego "significante" propio del "homo ludens".

- La vuelta al dia en ochenta mundos, p. 21.

-Los premios (Buenos Aires: Editorial Sudamericana; 10? ed., 1970, p. 164). 
Sin embargo, más allá del juego como forma de representación y como modo de colocación, está subyaciendo en la neutralización del gesto original del "outsider" típico, del "homo absurdus" que ha tenido en Kafka a su profeta, un problema mucho más profundo: es el cuestionamiento de la validez de la propia "inadecuación" como actitud vital. Toda palabra "significativa" resulta sospechosa y, aunque se llame juego, es ambigua en su esencia. Cortázar es el primero en cuestionar y corroer el lenguaje y las actitudes "significantes" que ha heredado y lo hace para devolver una gran interrogante burlona."

Si Jules Renard sospechaba que escribir un día "la hierba es verde" estaría cargado de dudas sobre si realmente la hierba es verde, no menos dudas tiene Cortázar sobre si puede ser válida la descolocación de sus personajes como un símbolo general de su ficción o la visión de los "mitos degradados" de la Argentina, tan infatuados en el gesto de los escritores que lo preceden en su cuestionamiento.

De alli tantas ambigüedades y desmentidos; de ahí, también, tantas ironías con que se castigan los propios personajes cortazarianos, siempre dispuestos a asociarse a la imagen que reflejan, para reirse de ella, pero ¿acaso hay algo más serio que la propia imposibilidad de tomarse uno realmente en serio?

Partiendo de una descolocación de este tipo, es difícil suponer que se pueda llegar al Cielo, pero se empieza a sospechar que -una vez más- es tan importante el camino como la llegada, el esfuerzo de su recorrido como la meta misma. Lo tealmente importante será, en cualquiera de los casos, no dejar de ser nunca el dueño del único privilegio reconocido para todo personaje de Cortázar: la infancia.

\section{Los Caminos de la Infancia Hacia el Cielo}

En el juego infantil de la rayuela se sabe que "en lo alto está el Cielo y abajo está la Tierra", pero también se sabe que "es muy difícil llegar con la piedrita al cielo", ya que "casi siempre se calcula mal y la piedra sale del dibujo".

- Uno de los ensayos más sugestivos publicados sobre Julio Cortázar es el de Graciela de Sola, Julio Cortázar y el bombre nuevo (Buenos Aires: Sudamericana; 1968), que habrá de citarse en varias oportunidades en este trabajo. Igualmente útil, especialmente en lo relativo al manejo de los símbolos del laberinto y de los monstruos en la obra de Cortázar, es el estudio de Néstor García Canclini, Cortazar: una antropologia poética (Buenos Aires: Editorial Nova, 1968). 
De ese juego y de esa dificultad está hecha la más clara y simple simbología de aspirar a "salvar las diferentes casillas" que separan a las dos orillas en que se mueve todo el esquema literario de Cortázar, especialmente en Rayuela. En la reconocida dificultad para cubrir los dos niveles está la densidad y la intensidad recurrente de toda su obra, aunque los ingredientes del juego original sean muy simples:

- una piedrita, la punta del zapato, un bello dibujo de tiza que puede aparecer dibujado en la vereda, en la calle, en los patios de París o de Buenos Aires y que ha llegado a ser propuesto como un verdadero "ser trashumante que persigue a Oliveira" al decir de Tirri." Oliveira la ve siempre: mientras camina por la rue de Sommerard o por Almagro, cuando piensa, mientras toma mate, mientras observa el vacío por una ventana.

- la infancia de quien juega a la rayuela, la única que otorga "la habilidad necesaria para salvar las diferentes casillas". Un problema surge entonces, "cuando casi nadie ha aprendido a remontar la piedrita hasta el Cielo se acaba de golpe la infancia y se cae en las novelas, en la angustia al divino cohete, en la especulación de otro Cielo al que también hay que aprender a llegar". ${ }^{8}$

La infancia parece facilitar un camino más directo al Cielo, especialmente cuando se jugaba a la rayuela en el Río de la Plata.

desde la infancia en Burzaco o en los suburbios de Montevideo mostraba la recta vía. del Cielo, sin necesidad de vedanta o de zen o de escatologías surtidas, si llegar al Cielo a patadas, Ilegar con la piedrita y en una última patada proyectar la piedra contra l'azur..."

Ahora bien, ese cielo cuyo color no es el azul, sino "l'azur", parece más cetcano de París que de Buenos Aires. Allí van los protagonistas de Rayuela, los de 62 Modela para armar y con París se comunican secretamente las "galerías" de "El otro cielo". El juego de la rayuela infantil, a la que el propio Cortázar reconoce un origen místico y religioso hoy desacralizado, cumple -en este sentido- una doble función de aproximación espacial y de abstracción simplificadora.

"Néstor Tirri en "El perseguidor perseguido", ensayo comprendido en La vuslta a Cortazar en nueve ensayos (Buenos Aires: Carlos Pérez, Editor, 1969).

8 Rayuela, p. 258.

I Ibid., p. 259. 
El VIA Je COMO "Sistema" de Fuga

Por lo pronto, el juego de la rayuela está reduciendo la distancia espacial real que recorre Oliveira en Rayzela,

- entre Buenos Aires y París (una ida ascendente que busca lo estelar desde lo telúrico)

- y entre París y nuevamente Buenos Aires (una vuelta o descenso que se descubre tardíamente como la auténtica ida). Porque, entre otras cosas, a París se lo cree un Cielo cuando se lo proyecta desde Buenos Aires, pero no es el Cielo cuando se vive realmente en París.

En este viđje Cortázar resume una búsqueda que ya está presente en forma alegórica en Los reyes, en muchos de sus relatos $\mathrm{y}$, muy especialmente, en Los premios. Se ha señalado en este sentido que Los premios constituye - como lo fuera el Adán Buenosayres de Leopoldo Marechal- una alegoría del viaje misterioso y breve en búsqueda de uno mismo a través de dos apasionantes vías: la liberación de todo falso pudor del lenguaje literario y la utilización del viaje como proceso mítico de aproximación a lo ontológico y a una Argentina que se dá como proyecto.

Claro está que el viaje, en la ironía cortazariana, puede ser también algo mucho más modesto: "Creo que necesito cambiar un poco de vida... y por eso decidimos embarcamos. Supongo que a casi todos les pasará lo mismo" se dice Paula en Los premios, ${ }^{10}$ aunque Claudio neutralice ese lugar común con otro:

Europa no ha de ser solamente los Uffizzi y la Place de la Concorde. Para mi lo es, por el momento, quizá porque vivo en un mundo de literatura. Pero quizá la cuota de desencanto sea mayor de la que una supone desde aquí.11

Lo importante es que desde Buenos Aires, ante la perspectiva de un viaje a Europa, las justificaciones se aparecen como posibles. Ante un río "color de caca chico", como es pintado el Río de la Plata, se pueden inventar los capítulos de "excusas" y postergar los verdaderos encuentros que la propia realidad de Europa impide postergar. Cortázar repite aquí un esquema alegórico de larga tradición rioplatense y con expresiones novelísticas variadas, especialmente desde la generación de escritores del 80: el cuestionamiento del "ser nacional", la "nostalgia"

10 Los premios, p. 117.

11 Ibid., p. 117. 
de una Europa que sólo se conoce por reflejo, la falsa sensación de "desterrado" y el obligado peregrinaje a París. Novelas como Sin rumbo de Eugenio Cambaceres lo hacen expresamente; otras de Arlt, Girondo, Filloy o del uruguayo Onetti lo manejan como un posible mecanismo de evasión, frustrado en la medida en que se realiza.

Porque el Cielo sólo puede estar en París antes de ir a Europa, luego inevitablemente se desplaza más lejos. Al medirse "con las columnas griegas", el resultado será hundirse "todavia más bajo". .El viaje, en tanto proyecto que se realiza, deberá siempre defraudar y Paula en Los premios se asombra de que "ciertos viajes no acaben en un tiro en la cabeza". ${ }^{12}$

Pese a lo exagerado de esta posible alternativa, es evidente que la obra de Cortázar reivindica un cierto placer por los viajes, por los cambios permanentes, por el gusto de la aventura por sí misma, configurando todo ello un sistema de "fuga" que viene condicionado por una dinámica que es una auténtica postura filosófica. Viajar puede ser una forma de afirmación de sí mismo frente a los otros — como se novela en 62 Modelo para armar- una metamorfosis que evita una continuidad frente a los otros.

El movimiento constante, el abordaje de realidades distintas, la acción de esfumarse a sí mismo para luego tratar de asumirse, tienen mucho que ver con la ruptura de esa "continuidad" que lo une a una determinada comunidad. En el caso de Cortázar - como tantos escritores argentinos - se trata de evitar una "predestinación" que lo encadena obligadamente al subdesarrollo de un país sudamericano, "a la decadencia de los escritores de un grupo filocolonialista proanglosajón" como reflexiona Persio en Los premios. ${ }^{13}$

Graciela de Sola insiste en que ese viaje puede ser un sistema de "fuga:" que logra concretarse en "El perseguidor". Johnny-Cortázar es el buscador del paraíso, de la felicidad y de la plenitud del ser. ${ }^{14}$ Se ha dado cuenta "para ese entonces de que mi destino era buscar" y esa búsqueda no es otra cosa que un rastreo en el espacio de un desvelo existencial por encontrar el propio yo. $Y$ los puntos que separan la Tierra del Cielo en la rayuela son sus obligados estadios.

12 Ibid., p. 118.

13 Con estas expresiones se alude duramente a un pleito no resuelto por el intelectual $y$ el escritor latinoamericano: el relativo a su radicación. Al expre. sarse de este modo la burla es notoria: se puede estar en esta "orilla" y el encadenamiento a una determinada comunidad ser más fatal oue el presunto desarraigo europeo.

14 Graciela de Sola (obra citada, p. 56), detalla la particular "zambullida en el embudo", al decir de Jorge Musto (Temas, Montevideo, no. 13, 1967), de Johnny y su particular "regreso de ese no-tiempo" que resulta terrible. 


\section{Un Desposamiento Existencial}

Es justamente la reducción espacial del juego de la rayuela la que permite hablar de una simplificación aritmética de una original complejidad conceptual, porque la progresión de los números de la rayuela y su nítida división en cuadriláteros supone - al abstraerlos_ el resumen de una preocupación existencial más vasta. Esa abstracción puede llegar a ser un "diseño interior" de Oliveira, al modo como lo insinúa Tirri, ${ }^{15}$ es decir, como un "reino-jardín-interior" del protagonista.

Esta abstracción supone también un despojamiento que propicia la simplificación aritmética. $\mathrm{Ha}$ sido Gudiño Kieffer quien ha visto en la obra de Cortázar un sucesivo inventario de "esos gestos desesperados y desesperantes por medio de los cuales el escritor arroja de si lo exterior, lo meramente circunstancial". ${ }^{16}$

En Rayuela el proceso es notorio: la apoyatura de objetos, notas y referencias culturales (jazz, lecturas, el "aparato". de un código recargado de nombres propios y significaciones "a priori") va cediendo a una condición humana desamparada, despojada de todo sostén cultural real, enfrentada directamente a un agujero, a un descenso abrupto. Entre París, un Cielo frustrado y lleno de "excusas" y desvíos culturales, y Buenos Aires - un infierno polarizado entre un Circo abierto al Cielo y un Manicomio que propicia un infierno más "esencial"- Oliveira se despoja, abstrae su visión existencial de toda posible excusa previa: enfrenta la matemática simple de una progresión numérica, la que le brinda el juego de la rayuela.

\section{la Espiral del Caracol}

Si bien la rayuela reduce la distancia espacial y permite enfrentar, al abstraerla, una preocupación existencial de la búsqueda del propio centro, el juego necesita del movimiento a lo largo de la distancia y del progresivo despojamiento. La experiencia oclusiva es dinámica, y lo que es más importante, no es recta. Se sospecha que una simplicidad perdida con la infancia, to ha sido en aras del "caracol" (hay rayuela caracol, rayuela rectangular, rayuela de fantasía. ${ }^{17}$ El camino recto al Cielo (si es que existe) se ha perdido con la infancia.

15 Obra citada en la nota 7.

16 "Las experiencias-límites de Julio Cortázar", reseña a Ultimo round, publicada en el diario El Pais (Montevideo, 1971).

17 Rayucla, p. 258. 
La búsqueda del Cielo y del propio centro supone un movimiento circular, en forma de laberinto o espiral, una construcción geométrica que ya aparece en el primer Cortázar de Los reyes, en tanto es "hermano de la jaula, de su prisión de piedra" y como hermano "de su cárcel misma" ha sido hecho por Dédalo ("astuto ingeniero") y se ofrece como un artificio. Pablo Rojas Guardia ha destacado la importancia del laberinto en la literatura latinoamericana como un símbolo mítico de todo lo que es enredo, maraña, caos, meandro, y lío 7 , refiriéndose a Cortázar, ha hablado de su "enfoque topológico y laberíntico" de la realidad. ${ }^{18}$

Pero el paralelo geométrico parece inevitable a un esquema filosófico mucho más amplio. Gastón Bachelard lo considera inherente a la intuición filosófica y a la propia condición de "espiral" del ser del hombre. "Una espiral? -escribe-. Expulsemos lo geométrico de las intuiciones filosóficas y regresará al galope", aunque descubra paralelamente que "en esta espiral ¡cuántos dinamismos se invierten! Ya no se sabe en seguida si se corre al centro o si se evade uno de él."19

Es esta justamente una de las claves de la inestabilidad del héroe cortazariano. Sería fáçil la búsqueda de un Cielo o un centro, aún girando sobre sí mismo -al decir de Jean Tardieu ${ }^{20}$ - si no existieran dudas sobre si realmente se está avanzando hacia el centro o ascendiendo hacia el Cielo. Desde Los reyes y por boca de Ariadna se sabe cómo "la entrada es lisa y fácil. Cuántas veces he llegado al punto en que la galería principal empieza a girar, a proponer el engaño sutilisimo".:21

El giro puede ser engaño, el movimiento constituir un alejamiento por inversión de la dirección pretendida. Teseo en Los reyes insiste en que "los hay que creen en galerías concéntricas, llenas de falsas puertas. Me aconsejaron caminar con los ojos cerrados para evitar las ilusiones; el instinto crece con la sombra y el desamparo"."22

Esa misma existencia circular, cargada de las dudas sobre si se está realmente avanzando sobre un centro o alejándose de él, agobiará siempre a los personajes de Cortázar. Suis múltiples preocupadas expresiones intentarán tender puntos de referencia en el contorno para edificar el "mandala" propio o el "centro sagrado", para sentir agobiados las "ex-

18 Pablo Rojas Guardia, La realidad mágica (Golpe de dados: Julio Cortázar) (Caracas: Monte Avila Editores, 1969), p. 29.

10 Gastón Bachelard, La poética del espacio (México: Fondo de Cultura Eco. nómica, 1963), p. 271.

20 "Pour avancer je tourne sur moi même Cyclone par l'inmobile habité" (Les témoins invisibles par Jean Tardieu, p. 36).

21 Los reyes (Buenos Aires: Sudamericana, 1970), p. 21).

22 Ibid., p. 30. 
pulsiones" de que son objeto en relatos como "Casa tomada" o el imposible acceso a la isla paradisiaca de " $\mathrm{La}$ isla a mediodía". En cualquier caso podrán repetir como el protagonista de "Preparativos de boda en el campo", de Franz Kafka, "la vida es un perpetuo giro que no permite darse cuenta en torno a qué se gira" o, como en el poema de Ezequiel Martínez Estrada, que "una fatalidad sin sentido aparente/ gira como los astros, por sobre todo y dentro/ de todo: cada ser es solamente el centro/ de esa rueda avatárica, de ese aro de serpiente". ${ }^{23}$

Ese mismo movimiento continuo y circular, aparentemente sin sentido o dirección fija, caracteriza a 62 Modelo para armar, la novela de un perpetuo viajar a través de un mosaico de fragmentos de capitales europeas que intentan componer "la ciudad", y también es la condición básica del enigmático viaje de Los premios.

El aparente gusto por la aventura y los cambios permanentes se constituye, de este modo, en un verdadero sistema de buisqueda. ¿Acaso no puede suponerse que la división en dos "pisos" de Oltimo round no es otra cosa que la simplificación absoluta de la raguela?: una tierra (planta baja) y un cielo (primer piso) sin etapas intermedias, sin escalones ni números.

Sin embargo, el propio sistema de búsqueda, desde el momento que es circular, consagra la ambigüedad inherente al movimiento y. puede llegar a permitir la inversión de un esquema al que respalda una mitología.

Oliveira se da cuenta en Rayuela que la geometría de lo borizontall (la espiral que busca el propio "omphalos" o centro umbical, previsto tanto como irradiación germinativa o como centro del laberinto, de acuerdo a la proposición de José Lezama Lima) o la geometría de lo vertical plasmada en la división Tierra-Cielo, puede no tener el sentido esperado de una metáfora objetiva que se pudiera recorrer a gusto.

"Se dio cuenta de que la vuelta era realmente la ida en más de un sentido", ${ }^{24}$ se dice para descubrir que la ida en este caso es el "descenso": tras un Cielo frustrado (París); aparece un Infierno (Buenos Aires donde encuentra todo mal y que se le aparece como una "puta encorsetada"). También en este esquema pueden aparecer las excusas: "en realidad no habia vuelto sino que lo habían traído". 25

A veces, ya se ha dicho, la búsqueda se revierte claramente en fuga,

23 En torno a Kafka y otros ensayos (Seix Barral, p. 101). Poema de Martínez Estrada leído por Enrique Moreno en la presentación del autor en confesencia sobre Henri Franck.

24 Rayuela, p. 274.

25 Ibid., p. 275. 
como logra "concientizar", aún asediado, el protagonista de "Instrucciones para John Howell". "¿Por qué estamos huyendo?", se pregunta, sabiendo además que la fuga puede ser infinita porque "más allá estaba el río, algún puente. No faltaban puentes ni calles por donde correr".26

Pero también se puede sospechar lo inverso: una fuga puede ser el modo que asume la búsqueda más auténtica, como en "El perseguidor",

cuando Johnny se pierde como esta noche en la creación continua de su música, sé muy bien que no está escapando de nada. Ir a un encuentro no puede ser nunca escapar, aunque releguemos cada vez el lugar de la cita. ${ }^{27}$

El juego es complejo en su aparente simplicidad: el personaje de Cortázar va realmente a un encuentro, aunque parezca que huye. Se em. pieza a sospechar que lo que importa más es la actitud que el movimiento, aunque para llegar a esa conclusión -es más importante ser que estar "alli" o "aqui" - hay que agotar otras etapas de este análisis. Lo que sigue es el desarrollo hacia esa conclusión.

\section{La Construcción del Templo}

Para muchas tradiciones que Cortázar invoca para destruir, el mundo ha sido creado desde un punto central (ombligo) desde donde habrian partido los rayos "germinativos" hacia las cuatro direcciones cardinales. Llegar, pues, al centro es $\tan$ importante como llegar a un esencial "punto de partida".

Las tres regiones cósmicas - Cielo, Tierra e Infierno- constituyen, paralelamente, un eje cuyo punto de intersección terrestre es una especie de "pilar del mundo", al decir de Mircea Eliade, desde el cual pueden contemplarse los extremos del eje y, a partir del cual, se edifican los templos del propio centro.

26 "Instrucciones para John Howell" (en Todos los fuegos el fuego, Buenos Aires: Sudamericana, 1966, p. 147).

27 "El perseguidot" (en Las armas secretas [Buenos Aires: Sudamericana, 1965], p. 133). Más adelante se precisa que "ahora sé que no es así, que Johnny persigue en vez de ser perseguido, que todo lo que está ocurriendo en la vida son azares del cazador y no del animal acosado. Nadie puede saber qué es lo que persigue Johnny, pero es así, está ahí, en Amorus, en la marihuana, en sus absurdos discursos sobre tanta cosa, en las recaídas, en el librito de Dylan Thomas, en todo lo pobre diablo que es Johnny y que lo agranda y lo convierte en un absurdo viviente, en un cazador sin brazos y sin piernas, ea una liebre que corre tras de un tigre que duerme" (p. 149). 
No es otra cosa que la "creación de un mundo" la que se preocupa a lo largo de Rayuela: la explícita construcción del "miandala". Ya se sabe que mandala significa círculo y que los tibetanos entienden ese círculo como "lo que rodea"; es decir, el centro buscado es uno mismo, el que lo construye a su alrededor. Cortázar lo dice directamente a través de la "morelliana" reflexión de

¿qué es en el fondo esa historia de encontrar un reino milenario, un edén, un otro mundo? Todo lo que se escribe en estos tiempos y que vale la pena leer está orientado hacia la nostalgia. ${ }^{28}$

Es una búsqueda de quienes siempre hablan de "nostalgias, de sapiencias lejanas como para que se las creyera fundamentales, de anversos de medallas, del otro lado de la luna siempre".

Muchos críticos de la obra de Cortázar han destacado la importancia del manejo de este mito, claramente explicitado por el autor. Sin embargo, no han señalado paralelamente lo inútil de esa búsqueda. Oliveira, Juan o Persio no pueden encontrar su centro y saltar de alli al Cielo por algo que padece de un modo a otro casi toda la literatura contemporánea: la falta de templos desde los cuales proyectar un esquema legitimo $\mathrm{y}$, sobre todo, estable, que se traduzca en una visión homogénea del mundo.

Cuando Oliveira llega a comprobar que es "terrible tarea la de chapotear en un círculo cuyo centro está en todas partes y su circunferencia en ninguna, por decirlo escolásticamente" ${ }^{29}$ lo que ha descubierto en definitiva es que no tiene centro y que no podrá tenerlo, aun planteada su ineludible necesidad. Su grito inmediato: "¿qué se busca?, ¿qué se busca? Repetirlo quince mil veces, como martillazos en la pared, ¿qué se busca?", será el anuncio de que el pretendido movimiento de ascenso personal se ha convertido en un confundido bracear sin dirección.

Los intentos de construir una "zona sagrada", un posible templo o "mandala" son, pese a todo, variados en la obra de Cortázar. La homologación más notoria es la de la "casa" con el Universo concentrado en

28 Rayuela, p. 446. Cortázar explicita muy claramente lo que llama el complejo de la Arcadia, el retorno al gran útero, "el back to Adam, le bon sauvage". $\mathrm{La}$ idea de un paraíso perdido o de la isla paradisíaca aparece burlonamente referida, pero buscada con igual tenacidad. Es indudable que la inocencia hollada que oscuramente se reivindica llorando y la tierra de Hurqalya pesan sobre el grupo que se reúne con la Maga y Horacio, del mismo modo que se insinuaba en relatos claves de Cortizar como "La isla a mediodia", un feliz resumen concentrado del mito de una "isla muy hermosa" de que habla Mircea Eliade en Mitos, sueños y misterios (Buenos Aires: Fabril Editora, 1961).

29 Rayuela, p. 577. 
"Casa tomada", de la que potencias sombrías pueden llegar a expulsarnos. Si es "Cefalea" se aclara que "entonces la casa es nuestra cabeza", el centro aparece aún más concentrado: las fuerzas invasoras no sólo atacan un reducto espacial mínimo - la casa habitación asimilada a un "centro del mundo" - sino que están en nosotros mismos, forman parte de una lucha resuelta con una "expulsión" o desprendimiento de parte de uno mismo.

Sin embargo, la forma más abierta de ese templo imposible es su propia parodia: un circo o un manicomio. Ambos, como el hogar primitivo que mantiene en su propio centro la abertura por la que asciende el humo de todo fuego, tienen su bueco: el central de la carpa en el circo, el hueco de un montacargas en el manicomio. Ambos propondrán en términos de paródica ironía una forma de evasión ascendente o descendente; ambos - finalmente - degradarán el mito de la construcción de una "imago mundi". La original religiosidad de tantas imágenes recurridas de Cortázar será, una vez más, desacralizada.

\section{El Círculo sin Centro}

Esa falta de un centro impide un orden general e instaura, en la terminologia de Cortázar, un "caos de bolsillo", ya intuido por Persio en Los premios:

Está seguro de que un orden apenas aprehensible por la analogía rige el caos de bolsillo donde un cantor despide a su hermano y una silla de ruedas remata en un manubrio cromado; como la oscura certidumbre de que existe un punto central donde cada elemento discordante puede llegar a ser visto como el rayo de una rueda. La ingenuidad de Persio no es tan grande para ignorar que la descomposición de lo fenoménico debería preceder a toda tentativa arquitectónica, pero a la vez ama el caleidoscopio incalculable de la vida. ${ }^{30}$

La idea de un punto central ordenador aparece unida a la idea de un círculo desplegado a su alrededor, una idea que no solamente es espacial (único aspecto que se analiza en este trabajo), sino que puede ser también temporal, una interesante faceta que simplemente dejamos anotada, abriendo un campo de futuras especulaciones. El mundo circu-

30 Los premios, p. 100. 
lar, como el tiempo circular está presente en muchas concepciones filosóficas. Schopenhauer, en $E l$ mundo como representación y voluntad, considera que

el tiempo es como un círculo que girara infinitamente; arriba hay un punto invisible que toca la tangente: el ahora. Inmóvil como la tangente, ese inextenso punto marca el contacto del objeto - cuya forma es el tiempo- como el sujeto, que carece de forma, porque no pertenece a lo cognoscible y es previa condición del conocimiento.

El tiempo circular gira infinitamente: el arco que desciende es el pasado, el que asciende es el porvenir; arriba hay un punto indivisible que toca la tangente que es el ahora. La misma idea de una "rueda" acompaña la cita de Jorge Luis Borges en "Nueva refutación del tiempo", cuando pone en boca de Visuddhimaga, autor budista del Siglo V, la cita probablemente apócrifa de que "la vida de un ser dura lo que una idea. Como una rueda de carruaje, al rodar toca la tierra en un solo punto, dura la vida lo que dura una sola idea". ${ }^{31}$

El interés de citar estos conceptos sobre el tiempo radica en el hecho de que con ellos se relativiza aún más la búsqueda del héroe de Cortázar. La correlación de las imágenes geométricas tiene siempre una consecuencia: el círculo que traza el personaje Oliveira, Persio o Juan, tratando de construir un orden sustitutivo del "caos de bolsillo", estaría a su vez insertado en ese otro punto móvil de la rueda temporal, con lo cual aquel "orden" estaría obligadamente en movimiento, es decir, en permanente cambio.

Otra variante de esta misma crisis del espacio está planteada por Cortázar en el "túnel" que propone en La vuelta al día en ochenta mundos, comunicando los extremos de lo infinitamente grande y de lo infinitamente pequeño, cura "por la física" del mal del antropocentrismo que caracteriza al siglo xx. "En los extremos del túnel habría un telescopio, por un lado, $y$ un microscopio por el otro". ${ }^{32}$ Ese túnel haría aún más absurda la realidad al integrar el presunto centro personal a la fantástica dimensión de lo inexplorado o solamente perceptible por la vía microscópica o telescópica.

En cualquiera de los casos, ese recorrido entre la Tierra y el Cielo

31 En Historia de la eternidad Borges propone otras teorias complementarias a su noción del tiempo, especialmente en los capitulos de "La doctrina de los ciclos" (p. 89) y "El tiempo circular" (p. 108).

${ }_{32}$ La vuelta al día en ocbenta mundos, p. 18. 
no tiene etapas intermedias. De ahí la importancia de entender la apuesta: "la flecha va de la mano al blanco: no hay mitad de camino, no hay siglo $\mathrm{xx}$ entre el $\mathrm{x}$ y el $\mathrm{xxx} .33$

Importancia que supone, sin embargo, un tiesgo: no dar en el blanco. En el salto del "alli" al "aqui" tampoco hay mitad de camino: las dos orillas están abiertas a un vacio humano, el océano que las separa y son la medida de las opciones que las separan radicalmente. Por a'go la Tierra y el Cieló no pueden llegar nunca a unitse, por algo Buenos Aires y París no logran conciliarse más allá de las galerías Güemes y Vivianne con que Cortázar parece querer comunicarlos más allá de todo espacio y de todo tiempo ("El otro cielo").$^{34}$

\section{Buenos Aires: la Ciudad que mira Hacia Europa}

El carácter de Buenos Aires, una ciudad cosmopolita abierta al río y al océano Atlántico, ha sido permanentemente cuestionado por una novelística que ha estado mirando hacia el mar, como si con ello pudiera cortar las barreras que la separan de Europa. Al margen de toda consideración sociológica sobre la base de una ciudad-puerto en la que recalaron vastos contingentes enmigratorios que nunca intentarian trasponer los límites urbanos para conocer otro país posible, hay numerosas referencias literarias que Cortázar resume en un ingenioso diálogo de Los premios.

Y más allá empieza Buenos Aires (dice uno de los pasajeros del Malcolm mirando a la ciudad desde la cubierta del barco). ¿No parece increíble?

-Incluso parece increible que digas empieza. Muy tápido te has situado en tu nueva circunstancia. Para mi el puerto siempre fue donde la ciudad se acaba. $\mathrm{Y}$ ahora más que nunca, como cada vez que me he embarcado y ya van varias.

-Empieza - repitió Paula— las cosas no acaban tan fácilmente. ${ }^{35}$

\footnotetext{
33 Rayuela, p. 576.

34 Se ha destacado que "El otro cielo' 'asume los rasgos de un relato clave en la literatura de Cortázar, especialmente en base a las propias palabras del autor que ha dicho que "los pasajes y las galerías han sido mi patria secreta desde siempre." Esa patria también tiene su "cielo"; "ya entonces era sensible a ese falso cielo de estucos y claraboyas sucias". Esas galerias se entrecruzan y superponen en el tiempo, entretejiendo una suerte de vía para la búsqueda del propio "centro" interior del personaje casi autobiográfico, por un lado, y "alter ego" de Lautréamont por el otro (véase el estudio de E. Rodríguez Monegal en este número).

${ }_{35}$ Los premios, p. 67 (el subrayado es nuestro).
} 
Del mismo modo, Raúl, más adelante reflexiona que "es curioso ver la ciudad desde el río. Su unidad, su borde complejo. Uno está siempre $\tan$ metido en ella, $\tan$ olvidado de su verdadera forma". ${ }^{36}$ En definitiva, un parecido empezar o acabar de La ciudad junto al rio inmóvil es el que ha llevado a Eduardo Mallea, en la novela de ese nombre, a construir su Historia de una pasión argentina a partir de una visión "atlántica": volcado al mar, en cuya costa vive, empieza a descubrir "detrás" de sí a un país invisible:

Quiere decir que había un hombre argentino visible y otro hombre argentino no visible, silencioso, obstinado, conmovido y laborioso en el fondo tremendamente extenso del país, en las estancias, las provincias, los pueblos, las selvas, los territorios. $Y$ aun en 12 ciudad, más en la ciudad profunda, no en la fácil, no en la inmediata. $^{37}$

El desconocimiento de ese país, que Mallea llama el "del caserío elemental" y de "Ia exaltación severa de la vida", ha llevado muchas veces a denunciar que "el rioplatense vive de espaldas a Latinoamérica", una actitud real que es muy fácil rastrear en toda la obra de Cortázar, como se lo ha hecho en la de Arlt, la de Borges, la de Onetti, ${ }^{38}$ la del propio Mallea y cuya aparente excepción —el Sábato de Sobre béroes y tumbases su mejor prueba: la desesperada búsqueda de identidad al través de un intento de integración nacional.

\section{¿Retroceder Primero?}

"El propio personaje de Circe es la Argentina -ha escrito Noé Jitrik a propósito del relato de ese nombre- un país profundamente natcisista que se autosatisface con la destrucción".39 Otros críticos cxtienden ese posible simbolismo al buque Malcolm de Los premtos. Un país que tenía un destino y se quedó sin él, un país de frustraciones, tripulado por frívolos conformistas o timoratos o, para el mejor de los casos, por tebeldes improvisados que van a un estéril sacrificio.

36 Ibid., p. 73.

37 Historia de una pasión argentina (Buenos Aires: Espasa-Calpe Argentina, Colección Austral), p. 62.

38 A propósito de Onetti véase "Los mecanismos de evasión", en Las tram" pas de Onetti, por Fernando Ainsa (Montevideo: Alfa, 1970).

39 "Notas sobre la zona sagrada y el mundo de los otros en Bestiario de Julio Cortázar", por Noé Jitrik, ensayo comprendido en La vielta a Gortázar en nueve ensayos (o.c.). 
El propio Cortázar ha sido drásticamente sincero en sus apreciaciones y se ha preguntado:

¿no deberiamos los argentinos ( $y$ esto no vale solamente para la literatura) retroceder primero, bajar primero, tocar lo más amargo, lo más repugnante, lo más obsceno, todo lo que una historia de espaldas al país nos escamoteó tanto tiempo a cambio de la ilusión de nuestra grandeza y nuestra cultura, y así, después de haber tocado fondo, ganarnos el derecho a remontar hacia nosotros mismos, a ser de verdad lo que tenemos que ser ${ }^{40}$

A esta forma en el tiempo de una Argentina "invisible", que lambién existe en el espacio, viaja Persio, sospechando una posible idcntidad, aunque - también- sospechando una posible falsediad en lia actitud vital esencial:

De cara a las estrellas, tirados en la llanura impermeable y cslípida, ¿operamos secretamente una renuncia al tiempo histórico, nos metemos en ropas ajenas y en discursos vacíos que cnguantan las manos del saludo del caudillo y el festejo de las efemérides, y de tanta realidad inexplorada elegimos el antagónico fantasma, la antimateria del antiespíritu, de la anti-argentinidad, por resueltal neg:tiva o padecer como se debe un destino en el tiempo, una citrera con sus vencedores $y$ vencidos ? $^{41}$

El juego de atracción y rechazo que en Mallea se define como una enfática opción a favor de la reivindicación del país "invisible", se divide en Cortázar mucho más ambiguamente entre un país realmente invisible y la retórica acumulada a su propósito. No basta optar por la Argentina "invisible", hay que saber además que hay tantas

dulces y tontas palabras folklóricas prefacio inconsistente de toda sacralidad, cómo se acarician la lengua con patas engomadas, crecen a la manera de la madreselva profunda, me libran poco a poco al acceso a la Noche verdadera, lejos de aquí y contigua, aboliendo lo que va de la pampa al mar austral. . ."

\footnotetext{
4a Luis Mario Schneider: "Entrevista a Cortázat", en Revista de la Universidad de México (mayo, 1963).

41 Los premios, p. 320 .

2 lbid., p. 250 .
} 
Ese cuestionamiento de la propia retórica acumulada a propósito del país "invisible" es gritado, más adelante, por el mismo Persio:

Todo me une porque todo me lacera, Tupac Amarú cósmico, ridículo, babeando palabras que aún en mi oído irreductible parecen inspiradas por Ia Prensa de los domingos o por alguna disertación del doctor Restelli, profesor de enseñanza secundaria. Pero crucificado en la pampa, boca arriba contra el silencio de millones de gatos lúcidos mirándome desde el reguero lácteo que beben impasibles, hubieta accedido acaso a lo que me hurtaban las lecturas. ${ }^{43}$

Es decir, hay un posible conocimiento del país "invisible" más allá de lo que se dice y supone acerca de él. Cortázar pretende ir más lejos que Mallea o el Martínez Estrada de Radiografía de la pampa y de $L_{a}$ cabeza de Goliat, reducidos a cierto sensorialismo expresivo a propósito del país que recorren. Sin embargo, también alude a un viaje inevitablemente pintoresco cuando dice:

He visto la tierra americana en sus horas más próximas a la confidencia última, he trepado a pie por los cerros de Uspallata, he dormido con una toalla empapada sobre la cara, cruzando el Chaco me he tirado del tren en la Pampa del Infierno para sentir la frescura de la tierra a medianoche.44

Cortázar, a través de Persio, está tomando aguda conciencia del ser histórico argentino que revierte en caos doloroso, en una especie de "noche primordial" del tiempo. AI no haberse resuelto en su intima contradicción, el tiempo aparece en un "presente indefinidamente postergado", en una suerte de no-ser. Dirá con rabia Horacio que "mi país es un puro refrito" y lo hará para rastrear la esencia de ese pastiche europeizante (por un lado) y los "cultos necrofílicos de la baguala y el bartio de Boedo".

El mismo Persio de Los premios llega a decirse:

Oh, Argentina, ¿por qué ese miedo al miedo, ese vacío para disimular el vacío? En vez del juicio de los muertos, ilustre de papiros, ¿por qué no nuestro juicio de los vivos, la cabeza que se rompe contra la pirámide de Mayo para que al fin la tercera mano

43 Ibid., p. 250.

4 Ibid., p. 251. 
nazca con un hacha de diamante y de pan, su flor de tiempo nuevo, su mañana de lustración y coalescencia? ¿Quién es ese hijo de puta que habla de laureles que supimos conseguir? ¿Nosotros, nosotros conseguimos los laureles? ¿Pero es posible que seamos tan canallas? 45

\section{El Pecado Original de ser Argentino}

Pese a estos intentos abiertos de integración es evidente que el personaje de Cortázar aparece cargado del complejo de inferioridad y de desajuste frente a la cultura europea de la que se cree reflejo directo. Cargados o no del "pecado original de América" de que ha hablado H. A. Murena, Horacio desde Buenos Aires y la Maga desde Montevideo han emprendido en Rayuela el típico ascenso que el esquema cultural rioplatense procura en relación ambivalente con Europa y su presunto centro sagrado: París.

Menos proyectado en el espacio, pero procurando también asumir una distancia frente al desajuste con Buenos Aires, el viaje de Los premios permite una comprobación más triste:

Todo estat preparado para hacer de este viaje algo como el intervalo entre la terminación de un libro y el momento en que cortamos las páginas de uno nuevo. Una tierra de nadie en que nos curamos de las heridas, si es posible, y juntamos hidratos de carbono, grasas y teservas morales, para la nueva zambullida en el calendario. Pero me ha salido al revés, la tierra de nadie era el Buenos Aires de los últimos tiempos. ${ }^{16}$

Cortázar está llamando a Buenos Aires "tierra de nadie", tal como ya hiciera en 1941 Juan Carlos Onetti en la novela de ese nombre. La tierra de nadie es, sin lugar a dudas, la gran ciudad ("estoy aqui en una ciudad cualquiera", se dice el personaje de Onetti), un monstruo donde se puede descubrir un secreto pregonado a voces: que la vida no tiene sentido y donde la sensación que domina al hombre es la de "estar en una casa cercada, en la trampa, sin esperanzas de huir". ${ }^{47}$ El esquema de Cortázar parece menos acosado que el de Onetti, aunque no menos "descolocado" en su origen.

45 Ibid., p. 252.

46 Ibid., p. 305.

75 Las trampas $d e$ Qnetti, p. 68 (o.c.). 
La esencia del dualismo del que se creen evadir los héroes de Cortázar, especialmente el Oliveira de Rayzela, está apoyada sobre una gran parodia: la cultura argentina, basada en el "truco por excelencia de la clase media" y en la rápida $y$ ansiosa acumulación de una cultura que no hace sino "hurtar el cuerpo a la tealidad nacional y creerse a salvo del vacío que la rondaba". ${ }^{48}$ Ese orden fariseo que esquivaba el fondo de los problemas mediante una especialización de cualquier orden, cuyo ejercicio confería irónicamente altas ejecutorias de argentinidad, ${ }^{\text {s }}$ es factor de descolocación a nivel nacional.

Oliveira, cuando vivia en Buenos Aires no hacía otra cosa que esquivar sin desmayo "el espectáculo de esa parcelación Tupac Amarú" no incurriendo "en el pobre egocentrismo (criollicentrismo, suburcentris. mo, cultucentrismo, folklorentismo) que cotidianamente se proclamaba en torno a él bajo todas las formas posibles".

Un sarcástico complemento de esta visión socio-cultural de la Argentina aparece en la reconstrucción que de su familia hace Oliveira, tefiriéndose a los "criollos de otros tiempos" como inevitablemente antisemitas, xenófobos y burgueses arraigados a una nostalgia de estanzuela.

En este marco, la imagen de Montevideo se aparece aún más desvalida, ya que está desprovista de la máscara o truco que esconde el vacio argentino real. La Maga ha salido de esa otra orilla del Río de la Plata, buscando su centro en París, dejando detrás suyo

las recovas de la Plaza Independencia, vos también las conocés, Horacio, esa plaza tan triste con las parrilladas, seguro que por la tarde hubo algún asesinato y los canillitas están voceando el diario en las recovas. ${ }^{31}$

Los ingredientes montevideanos son pobres: la lotería y todos los premios, la descuartizada de Salto, la política, el fútbol, una cañita de Ancap, ayudando a formar malamente el "color local" donde se insertan - casi a nivel de pesadilla ${ }^{52}$ - imágenes de un falso bucolismo, de un parodiado centro existencial, "una casa con patio y macetas donde mi papá tomaba mate y leía revistas asquerosas". ${ }^{.3}$

De casas asi se huge casi naturalmente, del vacío de esos escenarios

48 Rayuela, p. 25.

4 Ibid., p. 26 .

50 Ibid., p. 27.

51 Ibid., p. 74 .

52 Ibid., p. 58. "Si sueño con la escuela primaria, es tan hotrible que me despierto gritando", dice la Maga en el curso del mismo dialogado.

घ3 Ibid:, p. 58. 
se sospecha que no hay posible tescate, ni aún por la via del exotismo delitante que procuran las imágenes de Gregorovius:

A mí me suena raro el Uruguay, Montevideo debe estar lleno de torres, de campanas fundidas después de las batallas. No me diga que en Montevideo no hay grandísimos lagartos a la orilla del río. ${ }^{54}$

El Río de la Plata parece expulsar a sus habitantes, haciendo ineritable la búsqueda del centro y la construcción del propio mandala lejos de sus orillas barrosas, lejos de Montevideo o Buenos Aires. El intento de ascenso al Cielo por la vía que procura el "eje" Buenos AiresParis, parece ser la única solución de quienes viven en América como "desterrados". "América está integrada por desterrados y es destierro - ha escrito H. A. Murena en El pecado original de América- y todo desterrado sabe profundamente que para poder vivir debe acabar con el pasado, debe borrar los recuerdos de este mundo al que le está vedado el retorno, porque de lo contrario queda suspendido de ellos $y$ no acierta a vivir". .55

Esta condición de desterrado que Oliveira y la Maga tipifican es un modo de descolocación y proviene de algo que el mismo $\mathrm{H}$. A. Murena ha explicado:

he aquí los hechos, en un tiempo habitábamos en una tierra fecundada por el espíritu, que se llama Europa, y de pronto fuimos expulsados de ella, caimos en otra tierra, en una tierra en bruto, vacua de espíritu, a la que dimos en llamar América. ${ }^{56}$

\section{En el laberinto, Rumbo a París}

En el intento de ascenso original, cuando Horacio Oliveira decide ir a Paris, es evidente su aspiración de encontrar un centro existencial. Tanto Horacio como la Maga descubren que lo único importante era haber salido de Montevideo, ponerse frente a frente con eso que se llama modestamente "la vida". En este sentido "Montevideo era lo mismo que Buenos Aires y él necsitaba consolidar una ruptura precaria"s7 para empezar a dar lecciones "sobre la manera de mirar y de ver".

\footnotetext{
54 Ibid., p. 54.

55 El pecado original de América (Buenos Aires: Sur, 1954), p. 24.

56 H. A. Murena (o.c.), p. 163.

57 Rayuela, pp. 30 y 31.
} 
Cuando Oliveira llega a París empiezan las dificultades. Vive de prestado, "haciendo lo que otros hacen y viendo to que otros vern",s8 aunque no ha podido dejar de moverse "como una hoja seca", ${ }^{59}$ empezando a sospechar, poco después que "París era una enorme metáfora".

El laberinto de "rumbos babilónicos" — que ironiza Gregorovius con acidez- empieza a aparecerse "sin centro", aunque Honcio sigue creyendo adivinar que "en alguna parte de París, en algún día o alguna muerte o algún encuentro hay una llave" que "busca como un loco".60 Gregorovius acota que "fíjese que digo como un loco. Es decir que en realidad no tiene conciencia de que busca la llave, ni de que la llave existe. Sospecha sus figuras, sus disfraces; por eso hablo de metáfora."

Esa búsqueda fracasa: los movimientos en espiral de "Ja hoja seca" no acercan a Oliveira al centro del laberinto, sino que, por el contrario, terminan arrojándolo por un borde. Oliveira "empieza a darse cuenta de que cosas así (la llave) no están en la biblioteca"61 y que el laberinto de París no conduce a ningún Cielo.

En París difícilmente se supera la condición de "extraño". Lo hax comprobado la Maga:

en París somos como hongos, crecemos en los pasamanos de las escaleras, en piezas oscuras donde huele a sebo, donde la gente hace todo el tiempo el amor $\mathrm{y}$ después frie huevos y pone discos de Vivaldi, enciende los cigarrillos y habla como Horacio y Gregorovius $y$ Wong y yo... ${ }^{\text {a }}$

En su encuentro con la "clochard", donde Horacio sospechaba una posible comunicación entre el presunto Cielo de París y el auténtico Infierno, se descubre definitivamente que no hay "kibbutz". Hasta ese momento Oliveira había creído viable "fabricárselo" de un modo u otro; ahora descubre que "hace frío" y se recibe con "dolor" la única certeza: la condición de extranjero que la propia "clochard" le enrostra:

-Extranjero - dijo la clocharde, con menos simpatía por el nuevo- Español, eh, italiano.

-Una mezcla - dijo Oliveira, haciendo un esfuerzo viril por soportar el dolor. ${ }^{63}$

58 Ibid., p. 12.

59 lbid, p. 23.

60 Ibid., p. 161.

61 Ibid., p. 162.

62 Ibid., p. 227.

63 Ibid., p. 250. 
Si en Rayuela París no puede llegar a ser el "espacio sagrado" por excelencia, en 62 Modelo para armar, varios círculos concéntricos trazan sus lineas en el mapa de Europa y permiten sospechar un "mandala" para Juan.

París es percibido en esta novela en su justo sentido, es decir, desde el propio vacio que provoca el continuo deambular bohemio y profesional de Juan. Aquí la condición de "hoja al viento" es aceptada como un destino válido, como una forma posible de vida. Se puede vagar por Ia Porte de Lilas o Llellois Perret, Neuilly o Vincennes, derecha o izquierda, norte o sur.64 Ese París -al que se le da la categoría de "la Ciudad"- ofrece atisbos de la verdadera libertad buscada y contrapesos equívocos en sus manifestaciones subterráneas, como lo es un viaje en "metro":

ese París subterráneo que durante algunos minutos la llevaría a través de un sistema ineludible de pasajes y de vías, la aliviaba extrañamente de su libertad, le permitía quedarse como en ella misma, distraída y a la vez concentrada en esas últimas horas. ${ }^{05}$

Pero en definitiva, París defrauda, más allá del juego de equívocos con que se esquiva una comprobación final, la dramática pauta de las "dọs orillas" del rioplatense, a saber que "en Patís todo lo era Buenos Aires y viceversa".66

Mirar desde el fiel de la balanza los platillos oscilantes no parece recomendable, más cuando "en lo más ahincado del amor padecia y acataba la pérdida y el ovido". .7

\section{El Padre Argentino de Sienes Plateadas}

Una forma burlona de esquivar esa triste comprobación podría ser intentar asumir un "destino argentino" en París. Representar un país, como lo hacen los ridículos porteños de 62 Modelo para armar, paseando por Londres y París con "trajes a rayas y entallados" y peinados de un modo penoso ${ }^{68}$ llega a ser la caricatura de una dificultad existencial que se inventaría en muchos otros órlenes a lo largo de la obra de Cortázar

\footnotetext{
64 62 Modelo para armar (Buenos Aires: Sudamericana, 1968), p. 101.

65 Ibid., p. 102.

66 Rayuela, p. 26.

67 Ibid., p. 26.

6862 Modelo pata armar, p. 90.
} 
y que tiene sutilísimas implicancias en relatos como "Carta a una señorita en París", 69 o en parte del desajuste esencial de las culturas enfrentadas en "El otro cielo".

"Ustedes en París ya son bastante desagradables para un francés, con esos trajes argentinos a rayas y entallados - se dice en 62 Modelo para armar- para no hablar de la manera de peinarse. Aquí entre los londinenses resulta todavía más penoso". ${ }^{70} \mathrm{El}$ mismo traje puede inspirar una falsa seriedad y aplomo: "esa especie de padre argentino de sienes plateadas y trajes bien cortados que inspiran confianza". ${ }^{n} Y$ es que representar a un país es una de las cosas que Cortázar ha rechazado desde una cita de Jacques Vaché que encabeza Rayuela: "Rien ne vous tue un homme comme détre obligé de représenter un pays".

De cualquier modo, el argentino que escribe desde Buenos Aires a una "señorita que vive en París" puede alimentar un resentimiento aún más profundo. "Usted se ha ido a París - le dice el protagonista que vomita conejos con naturalidad-. Yo me quedé con el departamento de la calle Suipacha, elaboramos un simple y satisfactorio plan de mutua conveniencia hasta que setiembre la traiga de nuevo a Buenos Aires y me lance a mi a alguna otra casa donde quizás. .." Es de preguntarse, con este resentido precedente, si el hecho de "vomitar conejos" no puede ser un modo de expresar, desde Buenos Aires, que lo insólito y extraño es allí natural, en tanto en París seria sorprendente o imposible. De ese modo se rescataría para la capital argentina un privilegio de "atención" más concentrada que el que suele tener el "polo" de interés parisino. ${ }^{72}$

Pero en definitiva, para el héroe cortazariano París no es el Cielo, ni el "centro" donde puede levantarse el "templo" propio. La experiencia se va cerrando oclusivamente: un descenso, un tetorno se va imponiendo como inevitable. Volver a Buenos Aires es tal vez el modo de llegar al Cielo, pasando de largo por la Tierra y descendiendo al Infierno. Un universo circular depara, probablemente, este tipo de sorpresas, una paradoja que podría ser clave americana del templo nunca construido en su territorio.

\footnotetext{
69 Cuento de Bestiario (Buenos Aires: Sudamericana, 1951), p, 20.

7062 Modelo para armat, p. 90.

71 Ibid., p. 120.

72 Esta puede ser una variante de un relato rico en sugerencias, algunas de las cuales han sido señaladas por Alfred Mac Adam en $E l$ individuo $y$ el otro (Buenos Aires-New York: Ediciones La Libreria, 1971), p. 180.
} 


\section{"SeR" es más IMportante que "EstaR" aquí o allá}

En su retorno a Buenos Aires, Oliveira parece dispuesto a matat los "monstruos" de los que huyera originalmente y matarlos será para èl aceptarlos. Como el Minotauro de Los reyes que reflexiona en el centro del laberinto, Oliveira podría repetir: "Mira, sólo hay un medio para matar los monstruos: aceptarlos". ${ }^{73}$

"Para vivir en este orbe hay que quemar las naves del viaje - ha escrito Murena74-, hay que desautorizar espiritualmente lo que quedó atrás, pues éste es el nuevo mundo, y lo que aquí se hace es una nueva vida que de ninguna forma es continuación de la anterior. Matar o morir: no hay otra alternativa". Curiosamente, esta actitud "parricida" necesita del contacto con Europa que ha tenido Oliveira; necesita de su frustrada experiencia.

La imagen del retorno está unida, en este caso, a la de un descenso (o caida), un esquema de clara connotación cartográfica: Buenos Aires aparece hundida en una suerte de "agujero" espacial, al sur de un mapa o un globo terráqueo, cuya lógica no sobrepasa la de una sensación muchas veces repetida por los propios habitantes del Río de la Plata. Y el viaje de esta "vuelta", que es percibido como una auténtica "ida", lo efectúa Oliveira en barco, un modo de permitirle calibrar la verdadera dimensión del espacio recorrido, la imposibilidad de "una mitad de camino" sobre un vacio que sólo es océano.

Creyendo que podrá encontrar nuevamente a la Maga perdida en París, Oliveira recorre en el espacio de su escala en el puerto montevideano, los mismos escenarios del origen. No encuentra a la Maga, pero lo que es más importante es que intuye la imposibilidad absoluta de encontrar su centro paseando por un Montevideo aún más desasido y triste. El puntillazo final se lo da una música oída en un bar solitario: "Mi diagnóstico es sencillo, sé que no tengo remedio".

La misma idea de este progresivo descenso como toma de conciencia final de la "falta de remedio" está en Los premios. El buque Malcolm se va convirtiendo - aún viajando al azar- en un posible eje de comu-

73 Los ieyes, p. 64.

74 Murena (o.c., p. 24). Esta actitud "parricida" frente a Europa ha sido reiterada recientemente como "misión y responsabilidad del escritor", aunque sin citar el interesante precedente de Murena. Sin embargo, el propio ensayista y novelista argentino completaba esa tesis diciendo que "el parricidio no tiene sentido mas que cuando abre paso a una nueva vida, cuando se pronuncia la negación porque se lleva otra afirmación dentro, cuando se tiene inspiración, y si se lo practica como fría reiteración se incurre en lo solamente culpable, que no difunde más que muerte" (0.c., p. 35). 
nicación entre la Tierra y el Infierno. Su misteriosa popa, inaccesible y prohibida, tienta y atrae a los pasajeros. En un momento determinado, al lograrse abrir una puertecita que da a una escalera de caracol que desciende a las entrañas del barco, Raúl dice: "-De muchas maneras se baja aquí a la gehenna. Mientras esto no acabe también en un gigante tatuado, Caronte con serpientes en los brazos" ${ }^{76}$ Tras recorrer tenebrosos corredores, el mismo Raúl sospecha que "en realidad, lo único que nos falta es encontrarnos con el minotauro". ${ }^{76}$

\section{La Atracción del Vacío}

Pero en la "otra orilla", ni el Persio de Los premios, ni el Oliveira de Rayuela podrán encontrar el centro que los viajes no pudieron procurarles. Buenos Aires -es cierto- ofrece más rayuelas que París (se las ve en los patios del manicomio, desde las ventanas que parecen propiciar la violencia de un descenso suicida, un arrojarse final que podría ser el modo más directo de llegar al Cielo) y al asomarse una noche de Buenos Aires

para repetir en la rayuela la imagen misma de lo que acababan de alcanzar, la última casilla, el centro del mandala, el Ygdrassil vertiginoso por donde se salía a una playa abierta, a una extensión sin límites, al mundo debajo de los párpados que los ojos vueltos hacia adentro reconocían y acataban. ${ }^{77}$

Las experiencias se multiplican y aceleran. La pista del circo de Talita y Traveler intenta ser centro sagrado donde levantar el templo. Obviamente, la parodia queda convertida en su propia caricatura. Sin embargo,

cuando la primera noche se asomó a la pista aún vacía y miró hacia arriba, el orificio en lo más alto de la carpa roja, ese escape hacia un quizá contacto, ese centro, ese ojo como un puente del suelo al espacio liberado, dejó de reírse y pensó que a lo mejor otro hubiera ascendido con toda naturalidad por el mástil más próximo al ojo de arriba, y que ese otro no era él que fumaba

75 Los premios, p. 169.

70 Ibid., p. 170.

77 Rayuela, p. 385. 
mirando el agujero en lo alto, ese otro no era él que se quedaba abajo fumando en plena gritería del circo.7s

Tampoco será posible lograr la comunicación de los diferentes niveles y densidades procurados en el manicomio, donde poco después se intenta repetir la experiencia, matizada con el agravante de una obsesión creciente: la atracción por el bueco, agujero que comunica zonas del espacio vertical.

Talita se ha preocupado por Oliveira,

... y entonces bajamos al sótano. Horacio hablaba todo el tiempo del descenso, de esos huecos que lo preocupan. Estaba desesperado, Manú, daba miedo ver lo tranquilo que parecía, y entre tanto. .. Bajamos en el montacargas. . ${ }^{79}$

La misma atracción por el bueco facilita descensos:

Deteniéndose al lado del agujero del montacargas miró al fondo negto y pensó en los Campos Flegreos, otra vez en el acceso. En el circo había sido al revés, un agujero en lo alto, la apertura comunicando con el espacio abierto, figura de consumación; ahora estaba al borde del pozo, agujero de Eleusis, la clínica envuelta en vapores acentuaba el pasaje negativo, los vapores de solfatura, el descenso. ${ }^{80}$

De cualquier manera Cortázar neutraliza continuamente toda posible significación excesiva de cualquier valor puesto en juego; su burlona parodia es manejada también a propósito del "agujero". El "trascendente" acto de tomar mate, un rito que se forja alrededor del "agujero" del mate, le lleva en algún caso a proponer un orden del mundo "en su justa perspectiva" a partir del hecho de tomar mate. Oliveira lo cree en algún momento, revistiendo al hecho cotidiano de una sacralidad exótica que París procura. La propia habla popular ha consagrado burlonamente a la "filosofía del agujero del mate" como un esquema barato del filosofar. Basta, en este sentido, tomar mate en el Rio de la Plata para que se pierda la sacralidad parisina, tal como chatamente proponen los viajeros de Los premios: "Cuando a uno lo sacan de sus hábitos es como el pescado fuera del agua. Estoy muy acostumbrado al

so Ibid., p. 378. 
mate dulce de las cuatro".81 Pero la construcción de un mundo alrededor de ese agujero también fracasa por otros motivos: la movilidad del cebador impide tender los radios del "mandala" a partir de ese hueco portátil.

\section{EL Juego COMO ÚtTimo REDUCTo}

El juego de la rayuela es el último reducto al que se recurre en procura de la colocación buscada. Oliveira lo repite en todo momento, llega a caminar como si saltara a la rayuela ("una cosa tonta: encogiendo la pierna izquierda, avanzó a pequeños saltos por el pasillo"'s2) y multiplica sus intentos de llegar al Cielo hasta en el patio del manicomio, donde "levantando un pie" y riendo en voz baja, había saltado "de casilla en casilla". Extrañamente, en la oscuridad el dibujo de la rayuela "fosforecia débilmente".

Sin embargo, la repetición del juego parece irlo agotando y Oliveira percibe cómo el espectro de alternativas posibles se reduce en la medida misma de su acelerada combustión. Llegará el momento en que, asomado a una ventana, mirará hacia abajo y verá una rayuela con la silueta fantasmal de la Maga parada en su borde:

No se podia hacer otra cosa que mirar a la Maga tan hermosa al borde de la rayuela, y desear que impulsara el tejo de una casilla a otra, de la Tierra al Cielo. ${ }^{83}$

Ese "no poder hacer otra cosa" aparece por ptimera vez en el esquema cortazariano, abierto siempre a la sugerente aventura del salto en el espacio o el tiempo, al coqueteo inteligente con las fronteras que separan lo real de lo fantástico. Oliveira descubre aquí sin horror que "si me tiro voy a caer justo en el Cielo". ${ }^{84}$ Es decir, caer es ascender, como volver es ir. En definitiva, se empieza a sospechar que tal vez esté el Cielo en el Infierno, como el aqui de Buenos Aires puede ser el logro de lo absoluto que no puede plasmar el allá de París. Pero esta suposición no es una certeza; sería más fácil que lo fuera, aún invertida la verdad original.

$\mathrm{La}$ ambivalencia supervive hasta el final, como también el sentimiento

81 Los premios, p. 11.

82 Rayuela, p. 378.

83 Ibid., p. 407.

84 Ibid., p. 409 . 
que atrae a la forma de caida-ascenso. Ya se sabe que la búsqueda de lo absoluto siempre procura, en la medida que se cree que se la está logrando, un sentimiento ambivalente: miedo y alegria, atracción y repulsión.

Pero tal vez, al final de esta experiencia oclusiva de la obra de Cortázar haya otra conclusión agazapada por sobre el esquema de dos orillas separadas y un Cielo y un Infierno inaccesibles desde una Tierra no conocida. La búsqueda de quienes -como los héroes de Cortázar- hablan siempre de "nostalgias de sapiencias lejanas como para que se las creyera fundamentales, de anversos de medallas del otro lado de la luna siempre", no atriba nunca sino al punto de partida. Buenos Aires está al principio y al final del viaje de Los premios, también en el origen de la ida y vuelta de Rayuela, lo que supone en definitiva la construcción de caminos que sólo regresan y que algunos críticos proyectan en otro esquema bidimensional y opuesto de la obra de Cortázar: la evasión o la asunción real de la historia.

: Sin embargo, la conclusión parece ser otra. Esta búsqueda dinámica, este viaje circular, destruye el espacio y libera del "aqui" y del "alla" al hombre americano, particularmente rioplatense, para instalarlo en otra dimensión: el ser.

Con la rayuela se va de la Tierra al Cielo y sí Cortázar con la cita de Vaché, nos dice que la misión de Oliveira es hacer ver cómo se destruye un hombre que intenta vanamente representar a un país. Fernández Retamar ha señalado cómo con el propio título de Raytela se está indicando que la misión verdadera de Oliveira no es representar a un país, sino que su misión, como la de todos los hombres que ha habido en la tierra, es llegar al Cielo, es decir, salvarse, encontrar un sentido, encontrar una explicación. ${ }^{85}$

Ya José Lezama Lima había adelantado un aspecto de la destrucción del espacio al escribir que

Rayuela ha sabido destruir un espacio para construir un espacio, decapitar el tiempo para que el tiempo salga con otra cabeza. Es una novela muy americana que no depende de un espacio-tiempo americano. París o Montevideo, la hora de la salida del concierto - o la hora del amanecer, giran, ruedan y aseguran la igual concurrencia del azar. Evapora la tierra un espacio americano que no depende de una ubicación cruzada de estacas de nuestro conti-

85 "Sobre Julio Cortázar" (La Mesa Redonda No 3) Cuadernos de la Re. vista Casa de las Américas (La Habana, noviembre 1967), p. 52. 
nente. Por lo estelar desciende una cantidad que es lo temporal, océano final donde todo concurre a una cita. ${ }^{56}$

En este sentido Cortázar se inscribe nítidamente en el esfuerzo poético de recobrar la situación paradisíaca primordial. El poeta-descubre el mundo como si asistiese a la cosmogonía, pero no sólo como espectador, sino como creador. Todo gran poeta, ya se sabe que, en cierto modo, rebace el mundo. Sin embargo, ese rehacer parte de una premisa que es una verdadera conclusión a la que no llegan Persio, ni Juan, ni Oliveira, pero si el lector de Cortázar:

"¿Dónde está el peso mayor del "estar alli" - -se ha preguntado Bachelard ${ }^{87}$-en el estar o en el alli?" Uno de los términos siempre debilita al otro $y$ con frecuencia el alli (que puede ser perfectamente un aquí) está dicho con tal energía que la fijación espacial destruye brutalmente el aspecto ontológico esencial del problema: un ser nunca conjugado con la necesaria seguridad.

Solamente destruyendo el espacio y las falsas alternativas de sus opciones - comprometerse en ésta o la otra orilla a encontrar su centro o edificar su "mandala"- - permitirá al héroe de Cortázar ( $\mathrm{y}$ en su proyección al habitante del Río de la Plata) ser realmente y ordenar todo en su justa perspectiva. "Como los eléatas, como San Agustín, Novalis presintió que el mundo de adentro es la ruta inevitable para llegar de verdad al mundo exterior $\mathrm{y}$ descubrir que los dos serán uno solo cuando la alquimia de ese viaje de un hombre nuevo, el gran reconciliado" ha dicho Cortázar, pautando la superación de las categorías tiempo y espacio e intensificando la vía místico-poética como contacto con la realidad profunda.

Imaginar este milagro ya es parte de él y Cortázar lo sabe cuando se apresura a desmentir "morellianamente" toda conclusión excesiva del amable periplo de Rayuela:

Si el volumen o el tono de la obra pueden llevar a creer que el autor intentó una suma, apresurarse a señalarle que está ante la tentativa contraria, la de una resta implacable.88

Este desmentido es aún más tajante en Los premios:

\footnotetext{
86 "Cortázar y el comienzo de la otra novela", introducción a la edición de Rayuela, de Casa de las Améticas, ya citada.

87 Bachelard $\left(0 . c_{*}\right), p \cdot 271$.

88 Rayuela, p. 611,
} 
Mentira las verdades de los exploradores, mentira las mentiras de los cobardes y los prudentes; mentira las explicaciones; mentira los desmentidos.89

El explorador del Cielo y del Infierno, el viajero de América y París, deberá callarse con su posible verdad. El autor lo ha ordenado así para que la ilusa peregrinación futura de otros prosiga, ya fracasada de antemano. La bóveda celeste seguirá tentando al espacio terrestre, como los números progresivos de la rayuela seguirán siendo parte del juego de miles de niños, condenados un día a ser adultos "descolocados" en los brazos eternamente abiertos del símbolo de la Cruz que recorrieran saltando con tonta inocencia.

Fernando Ainsa

Montevideo, Uruguay.

Los premios, p. 402. 